\title{
Performance of age-matched controls on a battery of visuo-spatial neglect tests
}

\author{
S P Stone, P W Halligan, B Wilson, R J Greenwood, J C Marshall
}

\begin{abstract}
Examination of 47 independent elderly subjects, matched with a population of patients with acute stroke, found that $55 \%$ made at least one omission on a battery of neglect tests. Up to $43 \%$ made omissions on any one test. Increasing age and other evidence of cognitive impairment were associated with impaired performance on the battery. Omissions were attributed to an age-related decline in visuo-spatial function. Cut-off points are provided to distinguish between such age-related impairment and visuospatial neglect. The importance of agematched control studies in developing tests of cognitive impairment in stroke research is highlighted.
\end{abstract}

Patients with visuo-spatial neglect due to a unilateral cerebral lesion ignore relevant visual stimuli on the side opposite the lesion when performing simple everyday tasks. ${ }^{12} \mathrm{~A}$ test battery, the Behavioural Inattention Test (BIT), capable of detecting and measuring visuo-spatial neglect has recently been developed. ${ }^{34}$ It has been modified for use on patients with an acute stroke (see previous paper). Given that nearly half of all those suffering an acute stroke are over 75 years of age $^{5}$ and that age-related neurological ${ }^{67}$ and cognitive changes ${ }^{89}$ are common, it is necessary to know how the normal elderly perform on this test battery to interpret the findings observed in a stroke population of a similar age. Our study investigates this question.

\section{Method}

Forty seven controls were recruited. The mean (SD) age of the controls was 71.6 (12.77) years (range 34-93). Six subjects were left handed. Eight had been treated for hypertension; none had diabetes. Each was resident in the City and Hackney Health District, had no history of neurological disease, and was independent in selfcare. The sample was recruited from patients in general good health admitted for elective procedures or investigations (for example, joint replacements, cystoscopy, lithotripsy) to the urological and orthopaedic wards of St Bartholomew's hospital. Patients with a known neurological or psychiatric history or with a history of diseases known to have neurological manifestations (for example, adenocarcinoma of the kidney, carcinoma of the bowel or lung) were excluded. Those at risk of small vessel disease due to diabetes or hypertension were included as were those with cardiovascular disease for these are common disorders within the general and stroke populations. The sample was matched for age in 10 year cohorts with a population of 160 consecutive patients admitted to local hospitals with an acute stroke, mean (SD) age $72 \cdot 1(12 \cdot 6)$ years.

Subjects were examined for evidence of neglect phenomena such as visual and sensory extinction, hemi-inattention and allaesthesia ${ }^{1}$ and for related disorders (anosognosia, anosodiaphoria, non-belonging, visual field defects and gaze paresis). ${ }^{1}$ Each subject was administered, in the following order, the modified BIT; Kendrick's Object Learning Test (KOLT), which is a sensitive measure of diffuse brain pathology that correlates with other cognitive assessments; ${ }^{10}$ Hodkinson's Mental Test Score (MTS); ${ }^{11}$ and the Geriatric Depression Scale (GDS), which has been specifically developed for elderly people. ${ }^{12}$

Power, visual fields, cranial nerve function, light touch and reflexes were assessed in the standard manner at the bedside. ${ }^{13}$ Proprioception was measured by a method similar to that described by Mayne. ${ }^{14}$

"Hemi-inattention" was regarded as present if the subject's general spontaneous behaviour during examination suggested an inability to orientate or respond correctly to environmental stimuli on one side (for example, people approaching, noises or activity in the ward). ${ }^{1516}$ It was also regarded as present if the subject failed to shave or position their glasses properly on one side of their face; $;^{17}$ consistenly bumped into obstacles or doorways on one side when mobile; ${ }^{1518} 19$ appeared unaware of their contralateral limbs and let them remain in uncomfortable or unnatural positions. ${ }^{1}$

"Sensory extinction" was assessed by the technique of double simultaneous stimulation (DSS). ${ }^{13}$ Bilateral stimuli were given a total of five times and the number of correct responses out of five was recorded. "Visual extinction" was also assessed by double simultaneous stimulation on full confrontation testing, subjects being asked to report movement of the examiner's fingers. ${ }^{13}$

"Allaesthesia" was regarded as present if subjects consistently attributed sensory stimulation of one side to stimulation of the other or if they consistently moved the limbs on one side when requested to move the limbs on the other. ${ }^{1}$ The number of times that this happened during examination for sensorimotor deficits was noted. 
Anosognosia, anosdiaphoria and non-belonging were assessed by a modified version of Cutting's questionnaire. ${ }^{20}$ Gaze paresis was assessed by the ability of the subject to track a moving object (the examiner's finger) from right to left and back again, using a modified version of the method by DeRenzi et al..$^{21}$

The modified Behavioural Inattention Test is described in the accompanying paper. The Geriatric Depression Scale (GDS), ${ }^{12}$ the Mental Test Score (MTS) ${ }^{11}$ and Kendrick's Object Learning Test (KOLT) ${ }^{22}$ were also administered.

\section{Results}

1) THE NUMBER OF CONTROLS MAKING OMISSIONS ON EACH NEGLECT TEST

The number of controls making omissions was very small for most tests (table 1 ). The exceptions were Star Cancellation and Coin sorting. Twenty one controls made no omissions on any test, 12 made omissions on one test, 10 on two tests, two on three tests, one on four tests and one on six tests.

\section{2) THE NUMBER AND DISTRIBUTION OF} OMISSIONS ON EACH TEST

For most tests the number of omissions was very small (tables 1 and 2). Performance on Star cancellation (range $0-15$; mean 2.7 ; SD $4 \cdot 2$ ) and Coin sorting (range $0-3$; mean 0.4 ; SD 0.77 ) were exceptions. No control made a

Table 1 The number of controls making omissions on each neglect test, the range of omissions and cut-off points for abnormal visuo-spatial function

\begin{tabular}{llllc}
\hline $\begin{array}{l}\text { Neglect test } \\
\text { (maximum number } \\
\text { possible omissions) }\end{array}$ & $\begin{array}{l}\text { Number } \\
\text { controls } \\
\text { tested }\end{array}$ & $\begin{array}{l}\text { Number } \\
\text { making } \\
\text { omissions }\end{array}$ & $\begin{array}{l}\text { Range } \\
\text { of } \\
\text { omissions }\end{array}$ & $\begin{array}{l}\text { Cut-off } \\
\text { point }\end{array}$ \\
\hline Meal (8) & 47 & 2 & $0-1$ & 2 \\
Menu (24) & 47 & 0 & 0 & 1 \\
Lines (36) & 47 & 2 & $0-4$ & 5 \\
Stars (54) & 46 & 20 & $0-15$ & 16 \\
Coins (18) & 46 & 11 & $0-3$ & 4 \\
Pointing (180) & 47 & 1 & $0-50$ deg & 50 deg \\
L. Figure (6) & 47 & 0 & 0 & 0 \\
Newspaper & 47 & 1 & $0-1$ & 2 \\
a) Headlines (10) & 47 & 2 & $0-1$ & 2 \\
b) Paragraph (5) & 43 & 4 & $0-6$ & 7 \\
c) Article (117) & & &
\end{tabular}

Table 2 Age, KOLT score and numbers of omissions made by controls on neglect tests

\begin{tabular}{|c|c|c|c|c|c|}
\hline Test & $\begin{array}{l}\text { Number } \\
\text { omissions }\end{array}$ & $\begin{array}{l}\text { Number controls } \\
\text { making } \\
\text { omissions }\end{array}$ & Age & $\begin{array}{l}\text { KOLT } \\
\text { score }\end{array}$ & $\begin{array}{l}\text { Other } \\
\text { neglect } \\
\text { scores }\end{array}$ \\
\hline MEAL & 1 & 2 & 80 & 25 & $\begin{array}{l}\text { Point } 50 \\
\text { Stars } 3 \\
\text { Coins } 1\end{array}$ \\
\hline LINES & $\begin{array}{l}1 \\
4\end{array}$ & $\begin{array}{l}1 \\
1\end{array}$ & $\begin{array}{l}76 \\
65 \\
78\end{array}$ & $\begin{array}{l}33 \\
33 \\
22\end{array}$ & $\begin{array}{l}\text { Coins } 2 \\
\text { Stars } 2 \\
\text { Stars } 13 \\
\text { Coins 2 }\end{array}$ \\
\hline POINTING & 1 & 50 & 80 & 25 & $\begin{array}{l}\text { Meal } 1 \\
\text { Stars } 3 \\
\text { Coins } 1\end{array}$ \\
\hline HEADLINES & 1 & 1 & 78 & 22 & $\begin{array}{l}\text { Stars 13 } \\
\text { Coins 2 } \\
\text { Coins 2 }\end{array}$ \\
\hline PARAGRAPH & 1 & 2 & $\begin{array}{l}82 \\
74 \\
82\end{array}$ & $\begin{array}{l}11 \\
16 \\
11\end{array}$ & $\begin{array}{l}\text { Coins } 1 \\
\text { Stars } 6\end{array}$ \\
\hline ARTICLE & $\begin{array}{l}1 \\
2 \\
3 \\
6\end{array}$ & $\begin{array}{l}1 \\
1 \\
1 \\
1\end{array}$ & $\begin{array}{l}57 \\
82 \\
77 \\
78\end{array}$ & $\begin{array}{l}24 \\
25 \\
24 \\
22\end{array}$ & $\begin{array}{l}- \\
\text { Stars } 3 \\
\text { Stars } 10 \\
\text { Stars } 13 \\
\text { Coins 2 }\end{array}$ \\
\hline
\end{tabular}

Right Hand Start on Menu or Newspaper; one made a Right Hand Start on Line cancellation and three did so on Star cancellation. No control showed crowding on copying the left figure.

3) THE INFLUENCE OF AGE ON THE NUMBER OF OMISSIONS

Thirteen of 30 controls over the age of seventy made omissions on two or more tests, compared with two of 17 aged seventy or less. This difference was significant (Chi square $=4.85, \mathrm{p}<0.05)$.

In this sample, age had an effect on the number of missions made on Star cancellation (fig 1). Nine of the 29 controls over the age of seventy omitted six or more stars, compared with one out of the 17 aged seventy or less. This difference is significant at the 0.05 level (Chi square $=3.98$ ).

Although not statistically significant, a similar trend was observed on Coin sorting. Only 11 controls made omissions. Nine of them were aged over 70 and only two were 70 years old or less.

\section{4) RELATION OF KOLT AND MTS SCORES TO} NUMBER OF OMISSIONS ON EACH TEST

Declining KOLT scores (mean 31.26; SD 9.77; median 33.0; Q1 24.0; Q3 40.0) were significantly correlated with increasing age $(\mathrm{r}=-0.496 ; \mathrm{p}<0.01)$.

Declining KOLT scores were significantly correlated with an increasing number of omissions on Star cancellation $(r=-0.47$; $\mathrm{p}<0.01)$. Subsequent analysis showed that there was a cluster of high "star" scores (that is, six or more omissions) and declining KOLT scores (less than or equal to 27) (fig 2).

Table 2 shows that controls who made omissions on Meal, Line cancellation, Pointing, and all parts of the Newspaper task often had low KOLT scores (that is, less than 23: ref 22) or borderline KOLT scores (that is, 24-25).

The KOLT score did not correlate with the number of omissions on Coin sorting, although four out of six controls omitting two or more coins had KOLT scores of less than 23, compared with three out of 35 omitting less than two coins.

Thirty eight controls were assessed on the MTS. Thirty five scored at least nine out of 10 . One scored eight, had a KOLT score of 22 and

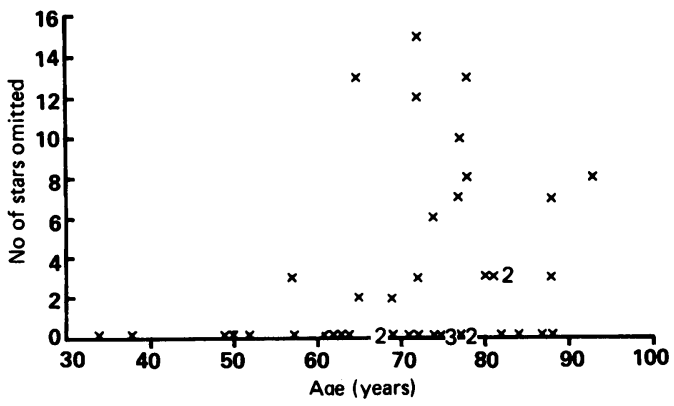

Figure 1 Relationship between age and the number of omissions on Star cancellation. 
Figure 2 Relationship between KOLT score and the number of omissions on Star cancellation.

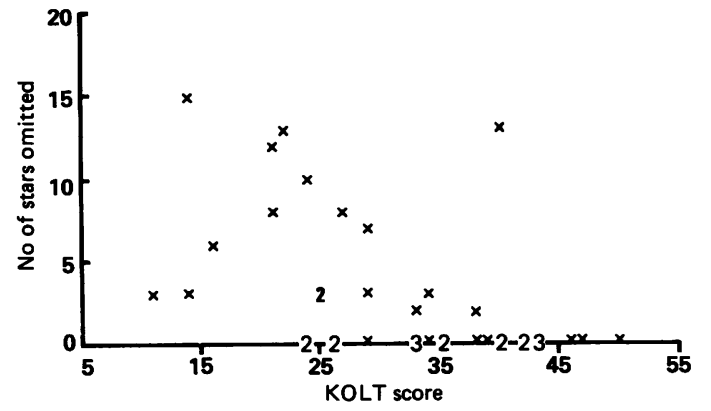

made four omissions on Line cancellation, one on Headlines, six on Article, two on Coin sorting, and 13 on Star cancellation. One scored six on the MTS, had a KOLT score of 40 but made 13 omissions on Star cancellation with a Right Hand Start. The remaining control scored five on the MTS, made seven omissions on Star cancellation but refused to do the KOLT.

5) EFFECT OF VISUAL ACUITY ON NEGLECT TEST OMISSIONS

Visual acuity, as measured by the ability to read small newsprint was adequate in all but four subjects. Two of these made no omissions on any other test. A third made one omission on Coins, one in Paragraph, three on Stars and had a KOLT score of 11 . The fourth made eight omissions on Stars and had a KOLT score of 21. Poor visual acuity thus remains a possible contributing factor in impaired performance in a few patients as noted by Eccles. ${ }^{23}$

\section{6) RELATIONSHIP BETWEEN NEGLECT TEST RESULTS}

The numbers of omissions made by controls on Coin sorting and Star cancellation were significantly correlated $(\mathrm{r}=0.41 ; \mathrm{p}<0.01)$. Table 2 shows that controls making omissions on one test often made omissions on other tests. Of the three controls with a Right Hand Start on Stars, one omitted 13 stars, the second had a Right Hand Start on Lines but made no omissions on any other test, and the third had a Right Hand Start on Stars in isolation.

\section{7) RELATION OF NEGLECT TEST OMISSIONS TO} NEUROLOGICAL FINDINGS

No control demonstrated any visual field defect, gaze paresis or cranial nerve palsies (corneal sensation was not tested). Two controls had minor signs of pyramidal tract damage without weakness. One of these omitted part of the daisy (but in a non-lateralised manner), the other made one omission on Meal and two on Coins.

Proprioception scores were 10 out of 10 in all limbs in 35 controls, and nine out of 10 in nine controls. One control (with sciatica) scored eight in one limb.

On testing for Visual Extinction, 44 (94\%) controls scored five out of five on DSS. Two scored 4/5 and one scored 3/5. Those scoring less than five all had low KOLT scores (14-21) and made large numbers of omissions on neglect tests (for example, three Coins, 15 Stars).

On testing for Sensory Extinction, 35 (75\%) controls scored five out of five on DSS; seven scored 4/5; three scored 3/5; one scored $2 / 5$ and one scored $0 / 5$. Some controls scoring less than five made no omissions on neglect tests and had normal KOLT scores. Many, however, either made large numbers of omissions on neglect tests (for example, eight stars, 13 Stars, two Coins, 50 degrees on Pointing) or had low KOLT scores.

No control showed hemi-inattention, allaesthesia, anosognosia, anosodiaphoria, nonbelonging, or gaze paresis.

8) RELATIONSHIP OF OMISSIONS TO DEPRESSION Four controls were depressed, with GDS scores of 5-8. One was aged 72, had a KOLT score of 14 , a visual extinction score of $3 / 5$ and made three omissions on Coin sorting and 15 omissions on Star cancellation. The other three were younger, aged 57, 62 and 64, and had KOLT scores of 23,23 and 24 respectively. Two of these made no omissions on any neglect test and the other made one omission on Article.

\section{9) PARAMETERS OF NORMAL VISUO-SPATIAL}

\section{FUNCTIONING IN THE ELDERLY}

The controls were regarded as normal by definition, and the range of omissions observed (table 1) was taken as the parameters of normal performance. Scores above this number of omissions on any one of the eight tests are considered abnormal. Thus two or more omissions on Meal; any omission on Menu; any left or right omission on Copying the Left Figure; five or more omissions on Line cancellation; 16 or more on Star cancellation; four or more on Coin sorting; two or more on Headlines; two or more on Paragraph; seven or more on Article; and 50 or more degrees on Pointing was regarded as abnormal. Right Hand Start on reading the Menu or Newspaper, and crowding of the Left Figures was also considered to be an indicator of abnormal performance.

\section{Discussion}

This group of subjects was selected as a control group for the stroke population for whom the test battery is intended. They were as representative as possible of the pre-morbid state of this local hospital-based stroke population, nearly all of whom $(89 \%)$ were active, independent and living at home. To that end they were matched for age, and were drawn from the same geographical area. They were in good general health, despite being admitted to hospital for routine repeat checks or other elective procedures.

This is one of the first studies to investigate visuo-spatial functioning in the elderly. Unlike other studies of neurological and cognitive function in the elderly this study recruited active and independent subjects, instead of 
medical inpatients, ${ }^{142}$ residents of elderly people's homes or institutions. ${ }^{25}$ In all these studies, depression, dementia or general illhealth might have affected the results of testing. Our controls were probably as active and independent as the "normal" elderly recruited from elderly people's clubs in other studies. ${ }^{22} 26$

A community study by Eccles ${ }^{23}$ of perceptual function in elderly people found that various tests of apraxia and spatial function were performed poorly or with difficulty by $18-59 \%$ of subjects. These included tests commonly used to detect visuo-spatial neglect such as drawing a clockface or a human figure, the Formboard and the Posting Box. Wade et al studied the performance of active independent elderly people in a number cancellation task designed to detect visuo-spatial neglect and found that $63 \%$ made omissions. ${ }^{26}$ Our findings are consistent with the results of both these studies. Fifty five per cent of our subjects made at least one omission on the entire battery. On one test, Star cancellation, $43 \%$ of subject made omissions. As with the study by Eccles, ${ }^{623}$ age and cognitive impairment influenced performance.

The performance of the controls was used to set the parameters with which to distinguish between normal and abnormal visuo-spatial function in the elderly. ${ }^{26}$ These parameters have been used to help define visuo-spatial neglect in patients with an acute stroke (see accompanying paper). The parameters of normal visuo-spatial function were set separately for each test, as visuo-spatial neglect has been shown to be task specific ${ }^{27}$ and may appear on one test but not on another. ${ }^{28}$

An age-related decline in neurological ${ }^{67}$ and cognitive function ${ }^{929}$ is well known. Beginning in their late sixties and seventies, ${ }^{9}$ elderly subjects show cognitive changes which often coexist without significant disease, disability or handicap ${ }^{30}$ and the same is true of neurological changes. ${ }^{31}$ A recent study of over 2000 elderly people showed that neurological signs consistent with diffuse cerebral disease are common but, taken in clinical context, are age-related and not pathological.

Such changes are often subtle and the concept of an "age-related decline in intellectual efficiency" $" 32$ is useful in accounting for findings such as visuo-spatial impairment, when they appear in clinical isolation. Visuo-spatial neglect may be due to a disruption of the "attention-arousal" system. ${ }^{1}$ "Attention" refers to a complex psychological construct ${ }^{33}$ whose neuro-anatomical pathways may be diffusely organised. ${ }^{133}$ It is reasonable to suggest that when the efficiency of this system is affected by age-related decline, subtle visuo-spatial impairments may appear on detailed clinical examination.

This work was supported by the Chest, Heart and Stroke Association (SPS). We thank Dr Ginny Wright, Memory Clinic,
Wittington Hospital, London, for advice on screening for Wittington Hospital, London, for advice on screening for
cognitive impairment and depression. Statistical help given by cognitive impairment and depression. Statistical help given by
Panna Patel, Department of Computer Studies, St BartholoPanna Patel, Department of Computer Studies, St Bartholo-
mew's Hospital. Assistance with graphics was given by Richard mew's Hospital. Assistance with graphics was given by Richard
Pottinger, Neurosciences Chief PMT, St Bartholomew's Hospital.
1 Heilman KM, Watson RT, Valenstein E. Neglect and related disorders. In: Heilman KM, Valenstein $\mathrm{E}$, eds. Clinical Neuropsychology. OUP 1985;243-50.

2 Leicester J, Sidman M, Stoddard LT, Mohr JP. Some determinants of visual neglect. J Neurol Neurosurg Psychiatry 1969;32:580-7.

3 Wilson B, Cockburn J, Halligan P. Development of a behavioural test of visuo-spatial neglect. Arch Phys Med 1987;68:98-102.

4 Wilson B, Cockburn J, Halligan P. Behavioural Inattention Test. Fareham, Hampshire. Thames Valley Test Company.

5 Bamford J, Sandercock P, Dennis M, et al. A prospective study of cerebrovascular disease in the community: the Oxfordshire Community Stroke Project 1981-86. Methodology, demography and incident cases of first ever stroke. J Neurol Neurosurg Psychiatry 1988;61:1373-80.

6 Howell TH. Senile deterioration of the central nervous system: a clinical study. $B M J 1949 ; 1: 56-8$

7 Jenkyn LR, Reeves AG, Warren T, Whitling RK, Clayton RJ, Moore WW. Neurologic signs in senescence. Arch Neurol 1985;42:1154-7.

8 Heron A, Chown S. Age and Function. London: J and A Churchill, 1967.

9 Schaie KW. The Seattle Longditudinal study. A 21 year exploration of psychometric intelligence in adulthood. In: Schaie KW, ed. Longitudinal studies of adult psychological development. NY: Guildford Press, 1983;64-135.

10 Kendrick DC. Psychological assessment. In: Pitt B, ed. Dementia. Edinburgh: Churchill Livingstone, 1987.

11 Hodkinson HM. Evaluation of a mental test score for assessment of mental impairment in the elderly. Age Aging 1972;1:233-8.

12 Yesavage JA, Brink T, Rose Tl, et al. Development and validation of a geriatric depression screening scale: a validation of a geriatric depression screening
preliminary report. J Psychiat Res 1983;17:37-50.

13 Swash M, Mason S (eds). Hutchinson's Clinical methods. 18th edition. London: Balliere Tindall, 1981.

14 Mayne $N$. Neuropathy in the diabetic and non-diabetic populations. Lancet 1965;ii:1313-6.

15 Battersby WS, Bender MR, Pollack M, Kahn RL. Unilateral "spatial agnosia" ("inattention") in patients with cerebral lesions. Brain 1956;79:68-93.

16 Hier DB, Mondlock J, Caplan LR. Behavioural abnormalities after right hemisphere stroke. Neurology 1983; 33:337-44.

17 Gordon WA, Hibbard MR, Egelko S, et al. Perceptual remediation in patients with right brain damage: a comprehensive programme. Arch Phys Med Rehabil 1985; 66:353-59.

18 Friedland RP and Weinstein EA. Hemi-inattention and hemisphere specialization: introduction and historical review. Advances in Neurology 1977;18:1-31.

19 Weinburg J, Diller L, Gordon WA, Gerstmann LJ, Liebermann A, Lakin P, et al. Visual scanning training effect on reading related tasks in acquired right brain damage. Arch Phys Med Rehabil 1977;58:479-86.

20 Cutting J. The study of anosognosia. J Neurol Neurosurg Psychiatry 1978;41:548-55.

21 DeRenzi E, Colombo A, Faglioni P, et al. Conjugate gaze paralysis in stroke patients with unilateral damage. Arch Neurol 1982;39:482-6.

22 Kendrick DC, Gibson AJ, Moyes ICA. The revised Kendrick Battery: Clinical studies. Brit J Soc Clin Psychol 1979;18:329-40.

23 Eccles JT. What is normal in the elderly? In: Wattis, Hindmarsh, eds. Psychological aspects of the elderly. Edinburgh: Churchill Livingstone, 1988 .

24 Stone SP, Wilson B, Rose FC. The development of a standard test battery to detect, measure and monito standard test battery to detect, measure and monitor
visuo-spatial neglect in acute stroke. Int $J$ Rehab Res visuo-spatial

25 Mehler MF, Bianco J, Ammerman PM, Wolfson LI. Selective association of hemi-neglect syndromes with multiple idiopathic falls in the institutionalized elderly. Ann Neurol 1985;18:125.

26 Wade DT, Wood VA, Hewer RL. Recovery of cognitive function soon after stroke; a study of visual neglect, attention span and verbal recall. J Neurol Neurosur Psychiatry 1988;51:10-13.

27 De Lacy Costello A, Warrington EK. The dissociation of visuo-spatial neglect and neglect dyslexia. J Neurol Neurosurg Psychiatry 1987;50:1110-6.

28 Ogden JA. Anterior-Posterior interhemispheric differences in the loci of lesions producing visual hemineglect. Brain and Cognition 1985;4:59-75.

29 Kral VA. Senescent forgetfulness. Benign and Malignant. Canad Med Assoc J 1962;86:257-60.

30 Sunderland A, Watts K, Baddeley AD, Harris JE. Subjective memory assessment and test performance in elderly adults. J Gerontol 1986;41:376-84

31 Broe GA, Akhtar AJ, Andrews GR, et al. Neurological disorders in the elderly at home. J Neurol Neurasurg Psychiatry 1976;39:362-6.

32 Blessed $G$, Tomlinson BE, Roth $M$. The association between quantitative measures of dementia and senile changes in the cerebral grey matter of elderly subjects. $B$ J Psychiat 1968;114:797-811.

33 Mesulam MM. The functional anatomy and hemispheric specialisation for directed attention. The role of the parietal lobe and its connectivity. Trends Neurosci 1983;6:384-7. 